\title{
Dietary Protein Restriction in Pregnancy Induces Hypertension and Vascular Defects in Rat Male Offspring
}

\author{
LEE BRAWLEY, SHIGERU ITOH, CHRISTOPHER TORRENS, ALISON BARKER, \\ CAROLINE BERTRAM, LUCILLA POSTON, AND MARK HANSON
}

Centre for Fetal Origins of Adult Disease, Level F, Princess Anne Hospital, Coxford Rd, Southampton

SO16 5YA [L.B., S.I., C.T., A.B., C.B., M.H.], and Maternal and Fetal Research Unit, Guy's King's St.

Thomas's School of Medicine, Kings College, London SE1 7EH [L.P.], United Kingdom

ABSTRACT

\begin{abstract}
It is established that dietary protein restriction of pregnant rats results in their offspring developing hypertension. However, to date no studies have investigated peripheral vascular function of offspring using the low protein model. Therefore, the aim of the study was to assess isolated resistance artery function from adult male offspring of control (C, 18\% casein) and protein-restricted (PR, 9\% casein) pregnant dams at two different ages. The birthweight of PR offspring did not significantly differ from that of C offspring. Systolic blood pressure was significantly elevated in PR compared with $\mathrm{C}(p<0.05)$. Maximal vascular contraction to phenylephrine and the thromboxane analog U46619 were similar in C and PR offspring at postnatal d 87 and 164. Relaxation induced by the endothelium-dependent vasodilators acetylcholine or bradykinin was significantly reduced in the PR group $(p<0.05)$. Relaxation to the endothelium-independent vasodilator sodium nitroprusside and phosphodiesterase type 3 inhibitor cilostamide was less in the PR offspring compared with $\mathrm{C}(p<$ $0.01)$. Dietary protein restriction in pregnancy induces hypertension and vascular dysfunction in male offspring. Abnormalities in the nitric oxide-cGMP pathway may explain the defect in endothelium-dependent and -independent relaxation. Reduced va-
\end{abstract}

sodilation may be a potential mechanism underlying the elevated systolic blood pressure observed in this model. (Pediatr Res 54: 83-90, 2003)
PE, phenylephrine
Abbreviations
ACh, acetylcholine
BK, bradykinin
SNP, sodium nitroprusside
NO, nitric oxide
KPSS, potassium PSS
PDE, phosphodiesterase
$\mathbf{P R}$, protein-restricted
C, control
CRC, concentration-response curves
$\mathbf{p E C}_{\mathbf{8 0}}, \mathbf{p E C}_{\mathbf{5 0}},-\log _{10}$ effective concentration of agonist to achieve $80 \%$ or $50 \%$ of the maximum response
$\mathbf{E C}_{\mathbf{8 0}}, \mathbf{E C}_{\mathbf{5 0}}$, effective concentration of agonist to achieve $80 \%$ or $50 \%$ of the maximum response
GC, guanylyl cyclase

Epidemiologic studies have shown that low birthweight is associated with increased risk of cardiovascular disease in adulthood $(1,2)$ and have led to the hypothesis that the fetal cardiovascular system undergoes programming in utero in response to unbalanced maternal nutrition. Fetal programming occurring at critical developmental stages may provide a survival strategy and serve to optimize growth, but it may also induce irreversible structural and physiologic changes (e.g. altering the renin-angiotensin system and hypothalamic-

Received June 4, 2002; accepted February 10, 2003.

Correspondence: Mark Hanson, Ph.D., Centre for Fetal Origins of Adult Disease (FOAD), Level F (Mailpoint 887),Princess Anne Hospital, Coxford Road, Southampton SO16 5YA, U.K.; e-mail: m.hanson@soton.ac.uk

Supported by the British Heart Foundation.

DOI: 10.1203/01.PDR.0000065731.00639.02 pituitary-adrenal axis) (3-5), resulting in abnormal cardiovascular control and peripheral vascular dysfunction postnatally. The link between low birthweight and elevated blood pressure has been widely confirmed (6).

Dysfunction of the vascular endothelium could contribute to the onset of hypertension or develop as a consequence. Endothelial cells are involved in the control of vascular tone through the release of endothelium-derived relaxant factors such as $\mathrm{NO}$ $(7,8)$, endothelium-derived hyperpolarizing factor (9), and prostacyclin (10). Endothelium-dependent relaxation was found to be impaired in hypertensive human subjects (11-14) and in vascular preparations from hypertensive rats $(15,16)$. As a consequence of fetal programming, vascular defects such as endothelial dysfunction may be present at birth, thereby increasing the risk of cardiovascular disease in adulthood. In a number of human stud- 
ies, low birthweight has been related to endothelial dysfunction in infants (17), children (18), and young adults (19).

However, the mechanisms underlying the association between fetal development and altered postnatal vascular function and cardiovascular disease remain unclear. Therefore, elucidation of the mechanisms of fetal programming of vascular defects necessitates the use of animal models. Previous studies have reported that endothelium-dependent relaxation was blunted in isolated arteries from the adult offspring of pregnant rat dams fed a global-restricted diet, and in addition, these animals were hypertensive $(20-22)$. However, the most widely used model is that of dietary protein restriction of pregnant rats, which results in their offspring developing hypertension (23-26), glucose intolerance $(27,28)$, and insulin resistance (27). To date no studies have investigated peripheral vascular function of such offspring of protein-restricted pregnant dams. We hypothesize that exposure to a proteinrestricted diet in utero may induce vascular defects in the resistance arteries of adult offspring, which may play a part in the maintenance of the elevated systolic blood pressure observed in this model.

Therefore, the present study was designed to assess the effect of dietary protein-restriction ( $50 \%$ protein) during pregnancy on isolated resistance artery function from rat male offspring. Vascular contraction and relaxant (endothelium-dependent and -independent) responses were evaluated in small mesenteric arteries from male offspring at $\mathrm{d} 87$ (young adult) and $\mathrm{d} 164$ (adult). Systolic blood pressure was measured in offspring (d 130) between these two ages to correlate with the vascular responses In this study only male offspring were studied as females were retained for studies of vascular function during pregnancy (28a).

\section{METHODS}

All animal procedures carried out in this study were in accordance with the regulations of the British Home Office Animals (Scientific Procedures) Act, 1986, and this study was approved by the local ethical review committee.

Animal and dietary protein restriction. Virgin female Wistar rats (Harlan Ltd, U.K.) weighing between 190 and $220 \mathrm{~g}$ were mated with male Wistar rats, and conception was confirmed by observation of a vaginal copulation plug. Pregnant rats were randomly divided into two dietary groups, housed individually, and fed control (C, 18\% casein) or low protein (PR, 9\% casein) diet throughout pregnancy. The constituents of the isocaloric experimental diets are as previously described by Itoh et al. (29). At term, the experimental rat diet (18 or $9 \%$ casein) was replaced with standard laboratory chow. Two days after delivery, rat pups were weighed, sexed, and culled to eight pups per litter. Offspring were weighed at regular intervals until experimental day.

Blood pressure measurement. In a subgroup of animals (d $130 \pm 5, \mathrm{C}, n=9$; PR, $n=8$ ), systolic blood pressure was measured by tail-cuff plethysmography using an IITC blood pressure monitor (229 model; Linton Instruments, U.K.) as previously described by Langley-Evans et al. (30).
Organ weight measurements. At postmortem examination, heart, lungs, liver, kidneys, pancreas, and adrenal glands were weighed. Organ weights are expressed as percentage of body weight.

Vascular function in isolated mesenteric vessels. Vasoreactivity of isolated mesenteric arteries was assessed in male offspring when d 87 (C-87, $n=8$; PR-87, $n=9)$ and d 164 (C-164, $n=9$; PR-164, $n=8$ ). One or two animals from each dietary group were randomly selected from five separate litters, and the remaining animals were used for other analysis. Each animal was killed by $\mathrm{CO}_{2}$ inhalation and cervical dislocation.

Preparation of rat mesenteric arteries and normalization. The mesenteric arcade was excised and immersed in ice-cold physiological salt solution (PSS) $(\mathrm{mM}): \mathrm{NaCl}, 119 ; \mathrm{KCl}, 4.7$; $\mathrm{CaCl}_{2}, 2.5 ; \mathrm{MgSO}_{4}, 1.17 ; \mathrm{NaHCO}_{3}, 25 ; \mathrm{KH}_{2} \mathrm{PO}_{4}, 1.18$; EDTA, 0.026; and D-glucose, 5.5. Small mesenteric arteries were dissected free of connective tissue and were mounted in PSS on a wire myograph (Multi Myograph Model 610M; J.P. Trading, Aarhus, Denmark) for recording of isometric tension as described previously by Itoh et al. (29). Mean internal diameter was similar in both groups at each time (C-87, $268 \pm 9 \mu \mathrm{m}, n$ $=8$; PR-87, $269 \pm 7 \mu \mathrm{m}, n=9, p>0.05$; C-164, $274 \pm 10$ $\mu \mathrm{m}, n=9$; PR-164, $259 \pm 9 \mu \mathrm{m}, n=8, p>0.05$ ).

Experimental protocol. The experimental protocol was carried out in the order specified below. Vascular contraction to $125 \mathrm{mM}$ KPSS (125 mM K, equimolar substitution of $\mathrm{NaCl}$ with $\mathrm{KCl}$ in PSS) and cumulative $\mathrm{CRC}$ to PE $\left(10^{-8}-10^{-4} \mathrm{M}\right)$ and the thromboxane $A_{2}$ mimetic, U46619 $\left(10^{-10}-10^{-5} \mathrm{M}\right)$, were carried out. The PE concentration used for precontraction was that required to produce $80 \%$ of the maximal response $\left(\mathrm{pEC}_{80}\right)$ induced by KPSS. Endothelium-dependent relaxation was assessed by ACh- $\left(10^{-9}-10^{-5} \mathrm{M}\right)$ and BK- $\left(10^{-12}-10^{-5}\right.$ $\mathrm{M})$ induced relaxation in PE-precontracted arteries. Endothelium-independent relaxation was determined by SNP $\left(10^{-10}\right.$ $\left.10^{-5} \mathrm{M}\right)$ and the PDE isozyme 3 inhibitor, cilostamide $\left(10^{-10}\right.$ $\left.10^{-5} \mathrm{M}\right)$, -induced relaxation in PE-precontracted arteries. The numbers of each arterial ring sample studied at each part of the protocol are shown in Table 1.

Drugs. All drugs and chemicals except cilostamide (Tocris Cookson, Avonmouth, U.K.) were obtained from Sigma Chemical Co (Poole, U.K.).

Calculation and statistical analysis. Contraction responses to agonists were calculated as percent of maximum $125 \mathrm{mM}$ KPSS-induced contraction and expressed as mean \pm SEM. Relaxant responses to agonists were calculated as percent inhibition of the PE-induced contraction $\left(\mathrm{pEC}_{80}\right)$ and expressed as mean \pm SEM. Two-way ANOVA was performed on all CRCs to ascertain whether the overall relaxation curves were different between dietary groups. CRCs to agonists were analyzed by fitting to a four-parameter logistic equation using nonlinear regression (Prism 3.0; GraphPad Software Inc, San Diego, CA, U.S.A.). Maximum responses and $\mathrm{pEC}_{50}$ values were then obtained, where the $\mathrm{EC}_{50}$ is the concentration (molar) of the agonist that produces $50 \%$ of its maximum response. Agonist concentration ratios were determined from $\mathrm{EC}_{50}$ values. When the curve produced by nonlinear regression was dissimilar to the unfitted data, curve-fitted data was not used. If curves were not sigmoidal, calculation of $-\log \mathrm{pEC}_{50}$ was 
Table 1. Vascular function in offspring of control and protein-restricted dams

\begin{tabular}{|c|c|c|c|c|c|c|}
\hline & \multicolumn{3}{|c|}{ Day 87} & \multicolumn{3}{|c|}{ Day 164} \\
\hline & $\mathrm{C}$ & PR & $p$ value & $\mathrm{C}$ & PR & $p$ value \\
\hline \multicolumn{7}{|l|}{ Maximal contraction } \\
\hline PE (\% KPSS) & $105 \pm 4(8)$ & $104 \pm 8(9)$ & 0.916 & $101 \pm 1(9)$ & $99 \pm 1(8)$ & 0.1792 \\
\hline U46619 (\% KPSS) & $104 \pm 7(7)$ & $87 \pm 6(7)$ & 0.090 & $93 \pm 2(9)$ & $97 \pm 2(8)$ & 0.1792 \\
\hline \multicolumn{7}{|l|}{$\%$ Relaxation } \\
\hline SNP (max relaxation) & $93 \pm 3(7)$ & $74 \pm 3(9)^{* * *}$ & 0.0006 & $67 \pm 3(9)$ & $72 \pm 12(8)$ & 0.6755 \\
\hline Cilostamide (max relaxation) & & & & $84 \pm 10(7)$ & $82 \pm 4(9)$ & 0.8550 \\
\hline \multicolumn{7}{|l|}{$\mathrm{pEC}_{50}\left(-\log _{10} \mathrm{M}\right)$} \\
\hline $\mathrm{PE}$ & $5.88 \pm 0.10(8)$ & $5.95 \pm 0.10(9)$ & 0.629 & $6.00 \pm 0.01(9)$ & $6.06 \pm 0.02(8)$ & 0.6050 \\
\hline U46619 & $7.83 \pm 0.05(7)$ & $7.53 \pm 0.03(7)^{* *}$ & 0.002 & $7.73 \pm 0.07(9)$ & $7.83 \pm 0.04(8)$ & 0.2400 \\
\hline $\mathrm{ACh}$ & $7.58 \pm 0.05(8)$ & $6.91 \pm 0.04(9)^{* * *}$ & 0.0001 & \multicolumn{2}{|c|}{ N/A } & \\
\hline
\end{tabular}

Values are given as mean \pm SEM. Statistical comparisons between $\mathrm{C}$ and $\mathrm{PR}$ at $\mathrm{d} 87$ and 164 , significance indicated by $* p<0.05, * * p<0.01, * * * p<$ 0.001 vs $\mathrm{C}$ maximum relaxation or $\mathrm{pEC}_{50}$ value.

Number in parentheses is number of observations.

$\mathrm{N} / \mathrm{A}$, calculation of $\mathrm{pEC}_{50}$ was not appropriate.

deemed inappropriate; CRCs were compared using two-way ANOVA (Prism 3.0; GraphPad Software Inc). Statistical analyses were performed using unpaired $t$ test to compare between groups and significance was assumed if $p<0.05$.

\section{RESULTS}

Offspring body and organ weights. Although the mean birthweight was $7 \%$ smaller in the PR group, it was not significantly different from that of the $\mathrm{C}$ group (birthweight, $\mathrm{C}$, $6.90 \pm 0.26 \mathrm{~g}, n=17$; PR, $6.44 \pm 0.30 \mathrm{~g}, n=17, p>0.05$ ). Pups appeared to remain smaller throughout adulthood, although this was only significantly different between groups at d 65 (body weight, C, $281 \pm 7.7 \mathrm{~g}, n=17$; PR, $238.6 \pm$ $11.0 \mathrm{~g}, n=17, p<0.05)$. There were no significant differences in individual organ weights between $\mathrm{C}$ and PR offspring at $\mathrm{d} 87$ (data not shown).

Blood pressure measurement. Offspring (d $130 \pm 5$ old) of PR dams had significantly higher systolic blood pressure compared with $\mathrm{C}$ offspring $(\mathrm{C}, 104 \pm 3 \mathrm{~mm} \mathrm{Hg}, n=9$; PR, $133 \pm$ $4 \mathrm{~mm} \mathrm{Hg}, n=8, p<0.05$ ).

Contractile responses. The maximal contraction induced by KPSS was found to be similar in C and PR groups at each time (Table 1). PE $\left(10^{-8}-10^{-4} \mathrm{M}\right)$ produced a concentrationdependent contraction of rat mesenteric arteries from both groups at $\mathrm{d} 87$ and 164 . There was no difference in PE-induced contraction between the $\mathrm{C}$ and the PR (two-way ANOVA, $p>$ 0.05 ) at $\mathrm{d} 87$ and 164 (Fig. 1 and Table 1). The thromboxane $\mathrm{A}_{2}$ mimetic, U46619 $\left(10^{-10}-10^{-5} \mathrm{M}\right)$ produced a concentration-dependent contraction of rat mesenteric arteries from both groups at $\mathrm{d} 87$ and 164 (Fig. 2). The overall contraction ( $p<$ 0.01 , two-way ANOVA) and sensitivity to U46619 was significantly reduced ( $p<0.01, t$ test) by 2 -fold in the PR offspring compared with $\mathrm{C}$ at $\mathrm{d} 87$ with no change in the maximum contraction (Fig. $2 A$ and Table 1). However, the overall and maximum contraction induced by U46619 was not affected in the $\mathrm{d} 164 \mathrm{PR}$ compared with C offspring ( $p>0.05$, two-way ANOVA; Fig. 2).

Endothelium-dependent relaxant responses. Basal tone or PE precontraction were unaffected by maternal protein deprivation or age (results not shown). The endothelium-dependent vasodilator, ACh $\left(10^{-9}-10^{-5} \mathrm{M}\right)$ produced a concentrationdependent relaxation of PE-precontracted arteries from $\mathrm{C}$ and PR offspring at $d 87$ and 164 (Fig. 3). The overall relaxant response $(p<0.001$, two-way ANOVA) and sensitivity to ACh was significantly reduced $(p<0.001, t$ test) in PR compared with $\mathrm{C}$ offspring at d 87 (Table 1). The ACh CRC from the PR group was shifted 5-fold rightward in relation to $\mathrm{C}$ (shift estimated from $\mathrm{EC}_{50}$ values) at $\mathrm{d} 87$. However, no significant difference in maximal relaxation to ACh was observed between the $\mathrm{C}$ and PR groups at $\mathrm{d} 87$ (Fig. $3 \mathrm{~A}$ and Table 1). At $\mathrm{d} 164$, the relaxant responses to $\mathrm{ACh}$ were shifted rightward and the percent maximum $(p<0.05, t$ test $)$ and overall relaxation ( $p<0.001$, two-way ANOVA) was significantly reduced in PR versus $\mathrm{C}$ (Fig. $3 B$ ). The overall CRC to BK $\left(10^{-12}-10^{-5} \mathrm{M}\right)$ was significantly reduced in PR compared with the $\mathrm{C}$ group at $\mathrm{d} 87$ and $164(p<0.0001$, two-way ANOVA; relaxation to $10^{-6} \mathrm{M} \mathrm{BK}, p<0.05, t$ test; Fig. 4 and Table 1). The BK-induced relaxation $\left(10^{-5} \mathrm{M}\right)$ was attenuated in the mesenteric artery from $\mathrm{C}$ and PR offspring at $\mathrm{d} 87$ and 164 (Fig. 4).

Endothelium-independent relaxant response. The endothelium-independent vasodilator, SNP $\left(10^{-10}-10^{-5} \mathrm{M}\right)$, produced a concentration-dependent relaxation of PE-precontracted rat mesenteric arteries from both $\mathrm{C}$ and PR offspring at $\mathrm{d} 87$ and 164 (Fig. 5). At $d 87$ and 164, the SNP curve was shifted to the right in the $\mathrm{PR}$ versus $\mathrm{C}$ offspring, with a significant reduction in the maximum relaxation occurring at $\mathrm{d} 87(p<0.001, t$ test; Fig. 5 and Table 1). There is a significant reduction in the control SNP response at d 164 compared with d $87(p<0.01$, 
A

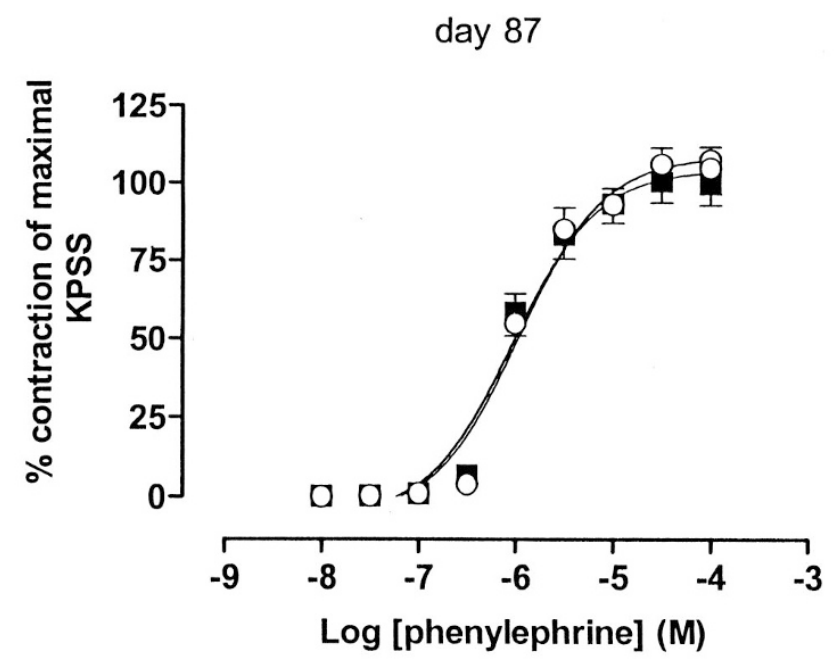

B

day 164

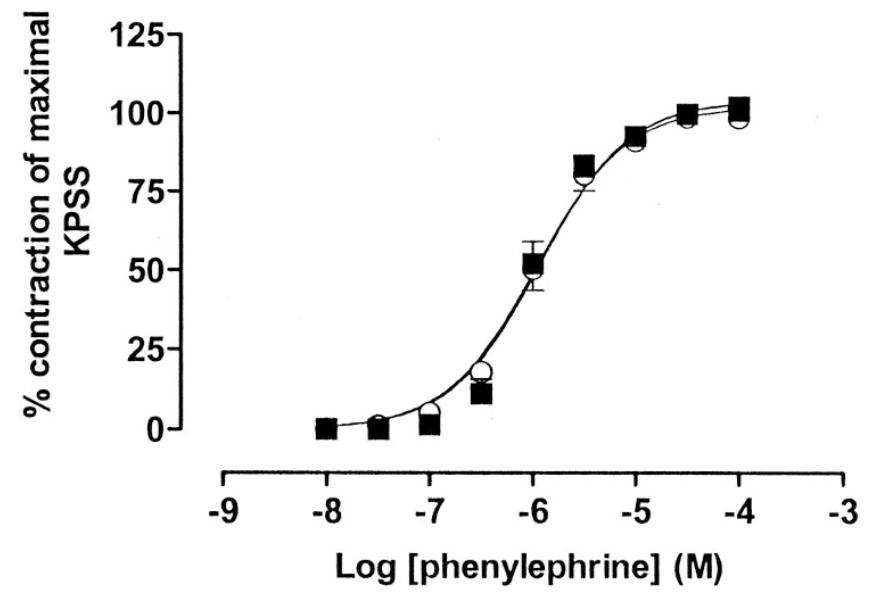

Figure 1. $A$, vascular contraction to $\mathrm{PE}$ in mesenteric arteries from male offspring aged d 87 in the $18 \%(O, n=8)$ and the $9 \%$ casein $(\square, n=9)$ groups. $\mathrm{C}$ vs PR overall relaxation via two-way ANOVA, $p=0.709 . B$, vascular contraction to $\mathrm{PE}$ in mesenteric arteries from male offspring aged $\mathrm{d} 164$ in the $18 \%(\mathrm{O}, n=9)$ and the $9 \%$ casein $(\square, n=8)$ groups. C vs PR overall relaxation via two-way ANOVA, $p=0.905$.

two-way ANOVA), and this trend is not observed in the PR groups.

Inhibition of cGMP degradation. The PDE 3 inhibitor, cilostamide $\left(10^{-10}-10^{-5} \mathrm{M}\right)$, induced relaxation in a concentration-dependent manner in both $\mathrm{C}$ and $\mathrm{PR}$ groups at $\mathrm{d} 164$ (Fig. 5C). There was a small, yet significant, reduction in the overall cilostamide-induced relaxation in the PR offspring compared with $\mathrm{C}$ offspring ( $p<0.05$, two-way ANOVA).

\section{DISCUSSION}

In the rat, maternal protein or global undernutrition in pregnancy is associated with reduced birthweight and elevated blood pressure in adult offspring $(22,25)$. To our knowledge, no study to date has evaluated the vascular function of isolated
A

day 87

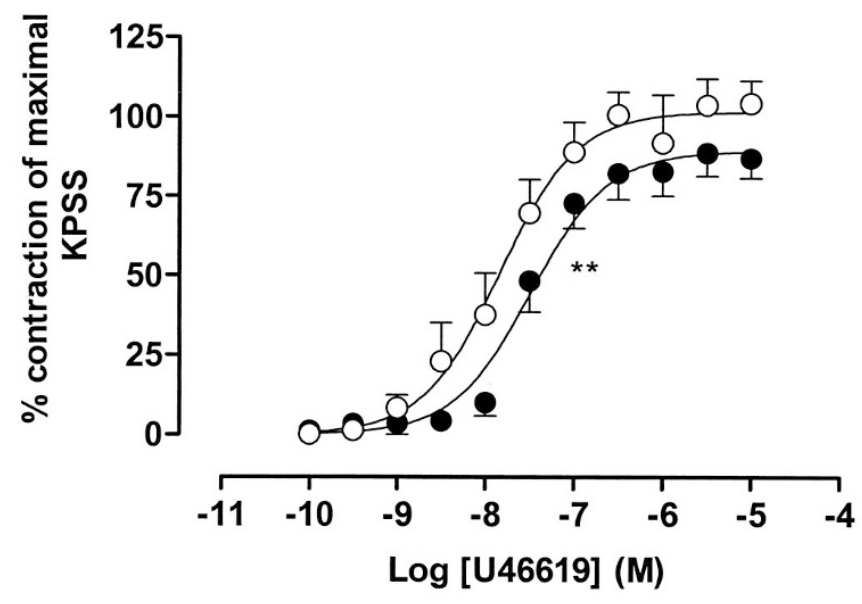

B

day 164

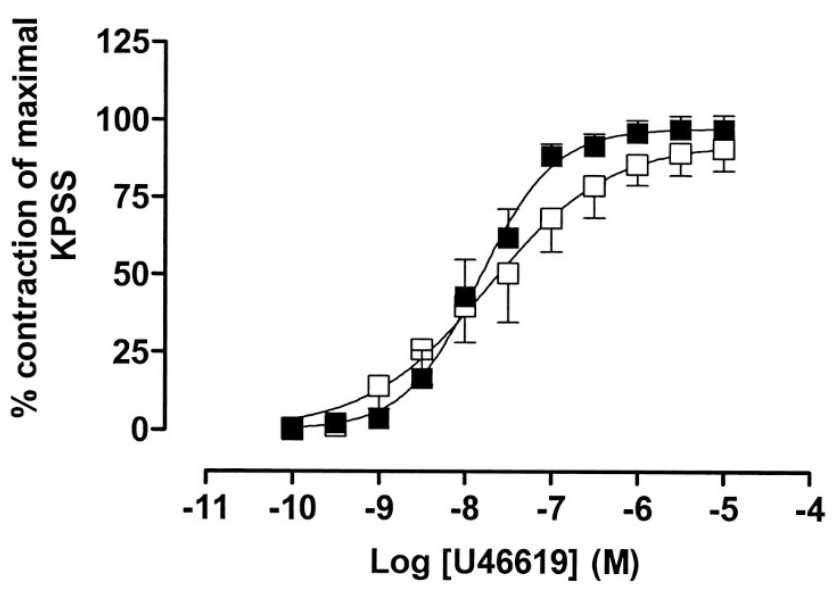

Figure 2. $A$, vascular contraction to thromboxane analog U46619 in mesenteric arteries from male offspring aged d 87 in the $18 \%(O, n=7)$ and the $9 \%$ casein $(, n=7)$ groups; $* * p<0.01$ vs control $\mathrm{pEC}_{50}$ value ( $t$ test). C vs PR overall relaxation via two-way ANOVA, $p<0.01$. $B$, vascular contraction to thromboxane analog U46619 in mesenteric arteries from male offspring aged d 164 in the $18 \%(\square, n=9)$ and the $9 \%$ casein $(\square, n=8)$ groups. C vs PR overall relaxation via two-way ANOVA, $p=0.166$.

mesenteric arteries from rats exposed in utero to maternal low-protein diet. The present study has shown that dietary protein restriction in pregnancy induces vascular defects in isolated resistance arteries and elevated systolic blood pressure in male adult offspring. It is therefore clear that programming of vascular defects occurs in this nutritional model, and this may contribute to the elevated systolic blood pressure observed postnatally.

Cardiovascular disorders such as hypertension and coronary heart disease have been related to low birthweight or smallness at birth, and these effects are seen in a graded manner across the natural birthweight range for the population, both in devel- 
A

day 87

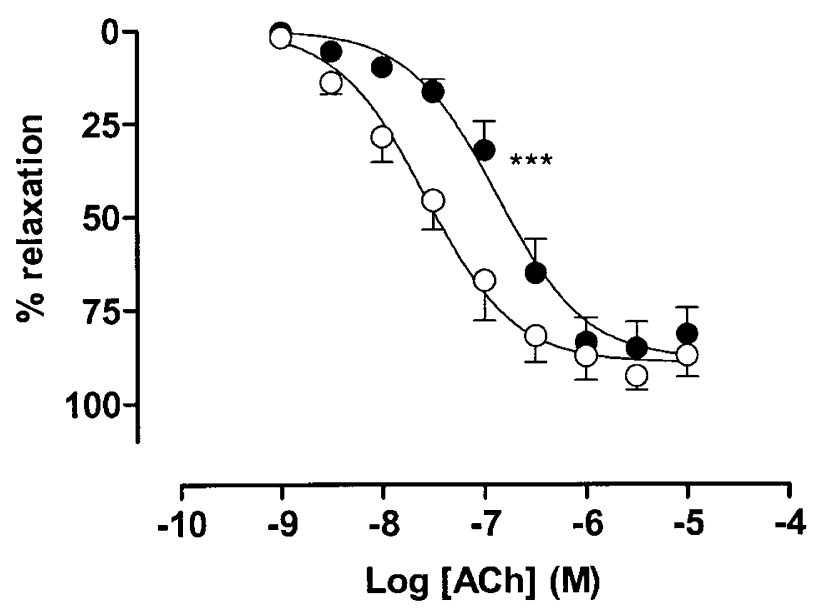

B

day 164

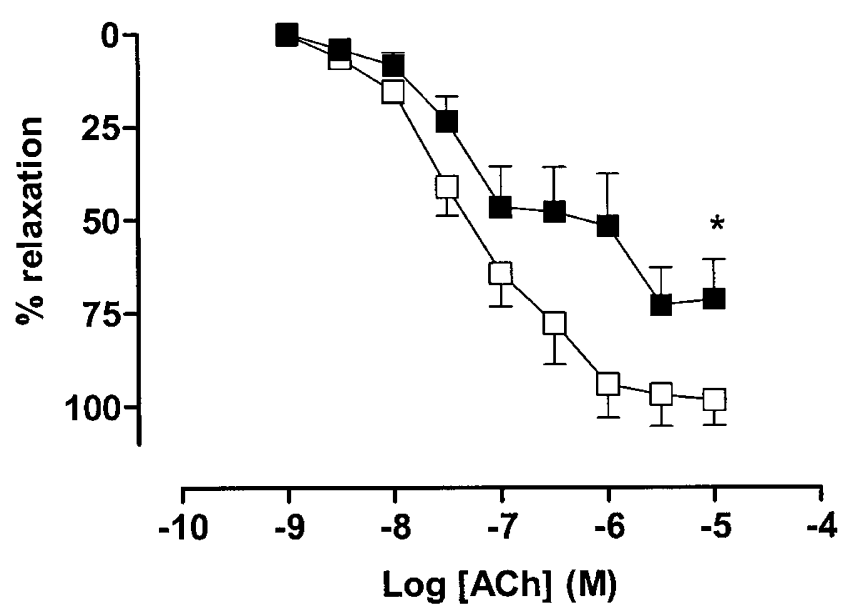

Figure 3. $A$, vascular relaxation to $\mathrm{ACh}$ in mesenteric arteries from male offspring aged d 87 in the $18 \%(\circ, n=8)$ and the $9 \%$ casein $(\bullet, n=9)$ groups; $* * * p<0.001 v s$ control $\mathrm{pEC}_{50}$ value $(t$ test). C $v s$ PR overall relaxation via two-way ANOVA, $p<0.001$. $B$, vascular relaxation to $\mathrm{ACh}$ in mesenteric arteries from male offspring aged d 164 in the $18 \%(\square, n=9)$ and the $9 \%$ casein $(\square, n=8)$ groups; $* p<0.05 v s$ control maximum relaxation at $\mathrm{d} 164$ $(t$ test). C vs PR overall relaxation via two-way ANOVA, $p<0.001$

oped and developing societies $(1,2)$. The phenomenon is not associated only with intrauterine growth retardation. In the present study, the birthweight of PR offspring did not significantly differ from that of the $\mathrm{C}$ offspring. Previous reports have shown that dietary restriction of pregnant rats results in inconsistent effects on birthweight, differing widely from study to study, in some cases showing a decrease $(25,31)$, but in others, no change $(24,32,33)$.

No significant differences in organ weights between $\mathrm{C}$ and PR offspring were observed at $d 87$ in our study. Our findings support these previous studies that noted no change in liver or
A

day 87

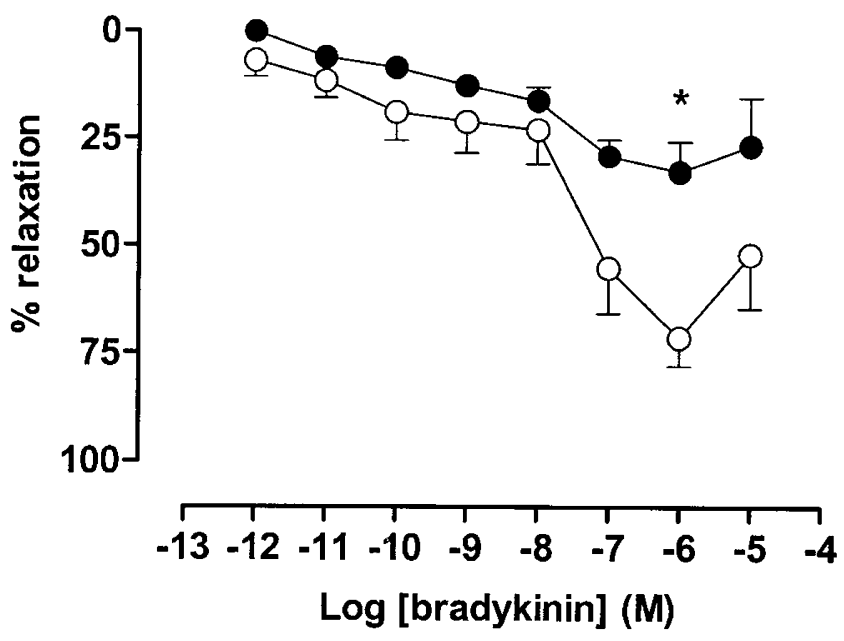

B

day 164

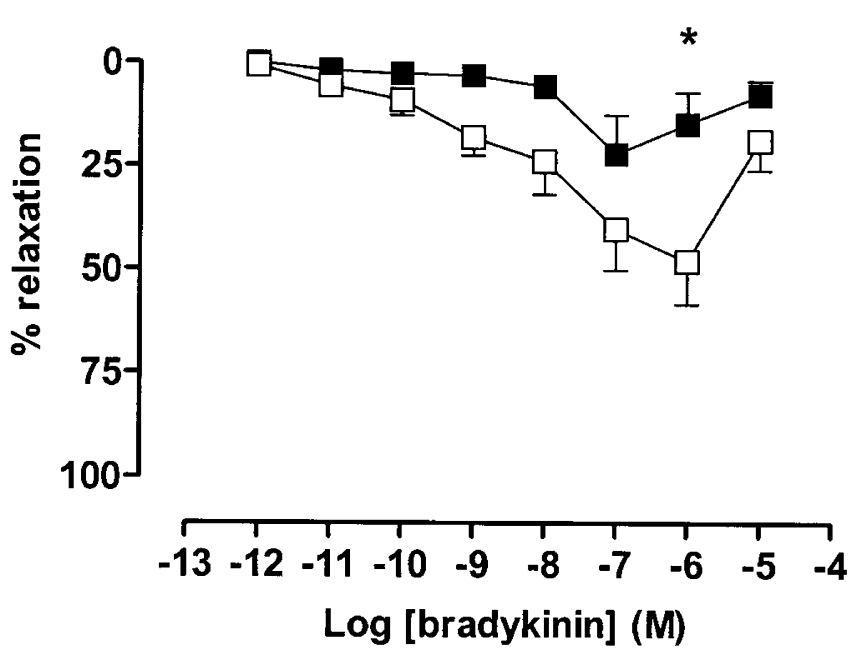

Figure 4. $A$, vascular relaxation to $\mathrm{BK}$ in mesenteric arteries from male offspring aged d 87 in the $18 \%(O, n=7)$ and the $9 \%$ casein $(\bullet, n=9)$ groups; $*_{p}<0.05 v s$ control $1 \mu \mathrm{M}$ BK-induced relaxation $(t$ test $)$. C $v s$ PR overall relaxation via two-way ANOVA, $p<0.0001$. $B$, vascular relaxation to BK in mesenteric arteries from male offspring aged d 164 in the $18 \%(\square, n=9)$ and the $9 \%$ casein $(\square, n=8$ ) groups; $* p<0.05 v s$ control $1 \mu \mathrm{M}$ BK-induced relaxation ( $t$ test). C $v s$ PR overall relaxation via two-way ANOVA, $p<$ 0.0001 .

other organ weights (34) of offspring of PR rats. Conversely, a reduction in kidney $(22,24,33)$ or liver size $(33,35,36)$ has been reported in offspring of dietary restricted pregnant dams. In some of these studies, the decrease in organ weight is reported at weaning, and this reduction appears to be restored to those of the control group as the nutrient-restricted offspring mature $(22,35)$. Therefore, in the present study, the time we selected was postweaning to investigate this. 


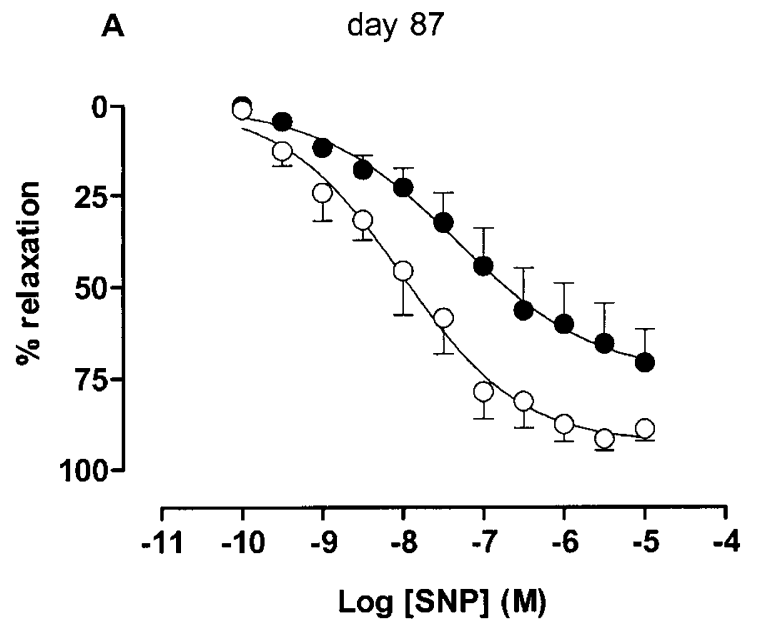

B day 164

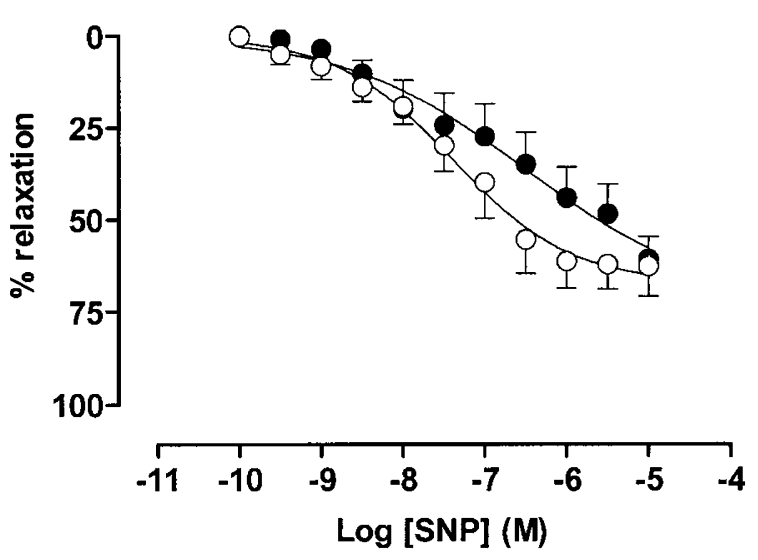

C day 164

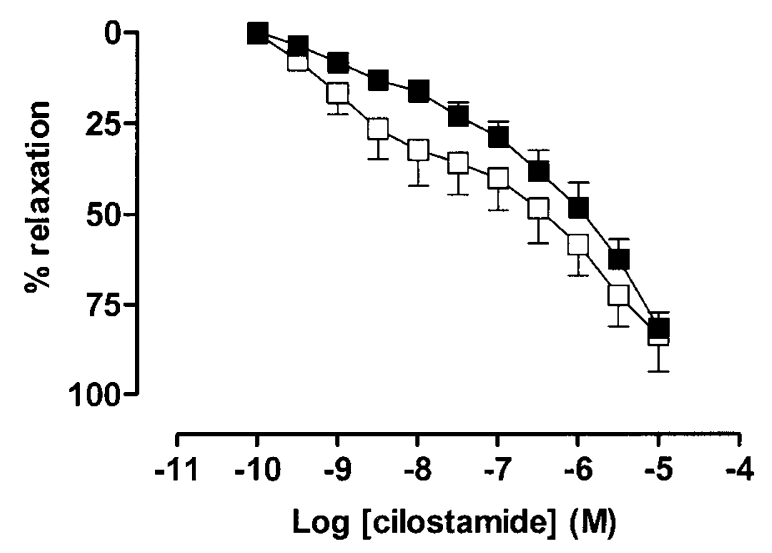

Figure 5. $A$, vascular relaxation to SNP in mesenteric arteries from male offspring aged d 87 in the $18 \%(O, n=7)$ and the $9 \%$ casein $(\bigcirc, n=9)$ groups; $p<0.01$ vs control $\mathrm{pEC}_{50}$ value $(t$ test), $p<0.001$ vs control maximum relaxation. C vs PR overall relaxation via two-way ANOVA, $p<0.01$. $B$, vascular relaxation to SNP in mesenteric arteries from male offspring aged d 164 in the $18 \%(\square, n=9)$ and the $9 \%$ casein $(\square, n=8)$ groups. C vs PR overall relaxation via two-way ANOVA, $p<0.01$. $C$, vascular relaxation to cilostamide in mesenteric arteries from male offspring aged d 164 in the $18 \%$ $(\square, n=7)$ and the $9 \%$ casein $(\square, n=9)$ groups. C vs PR overall relaxation via two-way ANOVA, $p<0.05$.
In the present study, systolic blood pressure was found be significantly elevated in PR compared with C offspring, which is comparable with previous studies using protein $(24,25,30$, $33,37-41)$ and global restriction during pregnancy $(21,22,42$, 43). Vascular dysfunction may not always be accompanied with increased pressor responses as observed in female offspring of global diet-restricted pregnant dams (20); however, these differences may be gender related as reported by Ozaki et al. (22). In the present study female offspring were not investigated as they were retained for studies during pregnancy (28a). In addition, direct comparisons between models should be treated with caution as there are differences in protocols used, e.g. severity and duration of undernutrition or vascular bed studied, and these may explain the differences in results obtained from each model.

In the present study, the vascular dysfunction in the mesentery may play a part in maintaining the elevated systolic blood pressure observed in male offspring of protein-restricted dams. However, it is unclear whether the impaired endotheliumdependent relaxation occurs first or develops as a consequence of cardiovascular disease. Langley-Evans et al. (30) reported that $\mathrm{d} 21$ protein-restricted offspring were hypertensive, but no vascular studies have been carried out at this stage of postnatal life. Nevertheless, low protein exposure in utero leads to vascular dysfunction in adulthood.

Consistently, the maternal low protein diet in pregnancy results in offspring being hypertensive $(24,25,41,44,45)$. Because the mesenteric circulation is known to contribute considerably to the control of peripheral vascular resistance (46), we chose this vascular bed to assess the vasoreactivity of small resistance arteries in PR and C offspring. The vascular dysfunction we found in the PR offspring may be attributed to an imbalance in the production of constrictors and dilators in the vascular bed. We did not detect any differences in maximum contraction to $125 \mathrm{mM}$ KPSS or responses to PE between the $\mathrm{C}$ and the PR groups at $\mathrm{d} 87$ and 164 . Previous investigations have also noted no abnormal $\alpha$-adrenergic-induced vasoconstriction in adult offspring of pregnant rats fed a high-fat (47) or a global-restricted diet $(20,22)$. Thus differences between $\mathrm{C}$ and PR groups are unlikely to be related to an increase in vascular smooth muscle cell growth or $\alpha$-adrenergic responsiveness.

Hypertension is associated with enhanced thromboxane production or thromboxane-induced constriction (48). However, in our study, a reduced sensitivity, although with a similar maximum response, to U46619 may suggest a disruption of thromboxane receptor-mediated contraction in the PR offspring at $\mathrm{d} 87$. This contrasts with increased contraction or no change in U46619 responses in isolated femoral arteries from adult male offspring of pregnant rats fed a global-restricted (18) or high-fat diet (36). Differences in protocols, e.g. severity and duration of undernutrition or vascular bed studied, may account for the contrasting results obtained from each model. In the present study, the reduced response to U46619 did not persist as the PR offspring matured. Similarly, in mesenteric arteries, thromboxane responses did not differ between male spontaneously hypertensive rats and control groups in 11-moold rats (49). Therefore abnormalities in the thromboxane- 
mediated pathway are unlikely to contribute to the elevated arterial pressure shown in the low protein model (25).

The vascular endothelium plays an important role in the control and modulation of vascular tone and hence in blood pressure regulation. Impaired endothelial-dependent relaxant responses, as shown in the low protein offspring in the present study, may be a causative factor in the development of hypertension and atherosclerosis (50-52), or alternatively, this attenuated vasorelaxation may have developed because of the elevated blood pressure (51). Previous studies have also noted that endothelium-dependent vasorelaxation is attenuated in the vasculature of offspring of pregnant rats given various dietary manipulations $(20,22,47,52 a)$. The significant blunting of $\mathrm{ACh}$ and $\mathrm{BK}$ relaxant responses in PR offspring may be attributed to a reduction in endothelial $\mathrm{NO}$ biosynthesis or $\mathrm{NO}$ bioavailability. Our findings are further supported by recent reports demonstrating a reduction in endothelial NO synthase expression and activity and increased oxidative stress in arteries from male offspring of pregnant rats fed a food-restricted diet $(21,53)$. Although we did not investigate the components of ACh- and BK-mediated vasorelaxation, our preliminary work indicates that ACh-induced NO release is significantly reduced in mesenteric arteries from protein-restricted pregnant dams compared with controls (54).

Disruption of NO synthase may explain in part the elevated blood pressure that was reported in offspring of pregnant rats exposed to a low protein $\operatorname{diet}(24,25,41,44,45)$. In the present study, in addition to $\mathrm{ACh}$ relaxant responses, BK-induced relaxation was severely impaired in PR offspring. In the spontaneously hypertensive rat model, $\mathrm{BK}$ and $\mathrm{ACh}$ responses were also greatly reduced when compared in mesenteric arteries (55). Vasodilation to BK is mediated partly by production of NO through stimulation of BK subtype 2 receptors $(55,56)$. However, when NO synthesis is reduced, ACh maintains endothelial vasodilator function in mesenteric arteries through activation of endothelium-derived hyperpolarizing factor in pregnant rats dams fed a protein-deficient diet (57). If this mechanism is also seen in the offspring, it may account for the differences between ACh and BK vasodilator defects. However, it is also well established that abnormal functioning of the BK receptor results in malfunction of the cardiovascular system. BK receptor function is crucial for the regulation of the cardiovascular system, as shown in BK receptor subtype 2 knockout mice in which elevated blood pressure was observed $(58,59)$. Further studies are indicated in which a detailed assessment of all components of ACh- and BK-mediated relaxation and NO measurement in PR offspring are made.

Maternal protein deprivation appears to induce abnormalities in the vascular smooth muscle function of the offspring. The endothelium-independent vasodilator, SNP-induced responses were reduced in the PR offspring, suggesting that there is a reduced NO sensitivity in the vascular smooth muscle. Abnormal SNP responses have also been observed in offspring of pregnant rats fed a high-fat (47), global-restricted (22) or protein-restricted diet (52a). Relaxant responses elicited by nitrovasodilator agents including SNP are mainly mediated via activation of soluble GC and subsequently an increase in intracellular cGMP levels (60). As previously shown in other animal models of hypertension, reduced endotheliumindependent responses are associated with a reduction in GC expression or intracellular cGMP concentration (61-65). Therefore, an alteration in the GC-cGMP pathway as shown in a previous study (52a) may account for the blunted relaxation to SNP observed in our study. Control animals show a greater reduction in SNP relaxation with aging; this may be caused by down-regulation of GC. Down-regulation of GC may already occur in young PR animals (d 87) as shown in young spontaneously hypertensive rats by Ruetten et al. (65), which may explain why the reduction in SNP responses in PR animals with age is smaller compared with that of the controls. We examined the effect of inhibition of cGMP degradation using a selective PDE 3 inhibitor, cilostamide (66). PDE 3 inhibitors induce relaxation in precontracted rat arteries $(67,68)$, and the magnitude of the relaxation induced by cilostamide in the mesenteric arteries thus indirectly reflects the intracellular levels of cGMP. Cilostamide-induced relaxation was significantly reduced in the PR offspring, further confirming our hypothesis that cGMP levels are reduced in the smooth muscle of mesenteric arteries from PR offspring compared with controls. Whether intracellular cGMP concentrations are reduced via down-regulation of $\mathrm{GC}$ remains to be determined.

\section{CONCLUSIONS}

In summary, this study has shown that protein deprivation during pregnancy in rats results in blunted vasorelaxation in small resistance arteries from male offspring. The cellular mechanisms underlying the defective vascular relaxation in the PR offspring may include a reduction in the endothelial NOcGMP pathway in vascular smooth muscle, and these together may lead to the development of cardiovascular disease. In addition, protein restriction in pregnancy alters other physiologic systems such as the renin-angiotensin system (40), which impacts on cardiovascular control. Therefore, attenuated vascular function may a play a part in this multifactorial process. Our findings suggest that impaired maternal diet programs the development of vascular dysfunction in their offspring.

\section{REFERENCES}

1. Barker DJ, Bull AR, Osmond C, Simmonds SJ 1990 Fetal and placental size and risk of hypertension in adult life. BMJ 301:259-262

2. Barker DJ 1997 Fetal nutrition and cardiovascular disease in later life. Br Med Bull 53:96-108

3. Langley-Evans SC 2001 Fetal programming of cardiovascular function through exposure to maternal undernutrition. Proc Nutr Soc 60:505-513

4. Bertram CE, Hanson MA 2001 Animal models and programming of the metabolic syndrome. Br Med Bull 60:103-121

5. Clark PM 1998 Programming of the hypothalamo-pituitary-adrenal axis and the fetal origins of adult disease hypothesis. Eur J Pediatr 157(suppl 1):S7-S10

6. Law CM, Egger P, Dada O, Delgado H, Kylberg E, Lavin P, Tang GH, von Hertzen H, Shiell AW, Barker DJ 2001 Body size at birth and blood pressure among children in developing countries. Int J Epidemiol 30:52-57

7. Furchgott RF, Zawadzki JV 1980 The obligatory role of endothelial cells in the relaxation of arterial smooth muscle by acetylcholine. Nature 288:373-376

8. Ignarro LJ, Lippton H, Edwards JC, Baricos WH, Hyman AL, Kadowitz PJ, Gruetter CA 1981 Mechanism of vascular smooth muscle relaxation by organic nitrates, nitrites, nitroprusside and nitric oxide: evidence for the involvement of $S$-nitrosothiols as active intermediates. J Pharmacol Exp Ther 218:739-749

9. Nagao T, Vanhoutte PM 1993 Endothelium-derived hyperpolarizing factor and endothelium-dependent relaxations. Am J Respir Cell Mol Biol 8:1-6

10. Moncada S, Gryglewski R, Bunting S, Vane JR.1976 An enzyme isolated from arteries transforms prostaglandin endoperoxides to an unstable substance that inhibits platelet aggregation. Nature 263:663-665 
11. Panza JA, Quyyumi AA, Brush JE, Epstein SE 1990 Abnormal endotheliumdependent vascular relaxation in patients with essential hypertension. N Engl J Med 323:22-27

12. Taddei S, Virdis A, Mattei P, Salvetti A 1993 Vasodilation to acetylcholine in primary and secondary forms of human hypertension. Hypertension 21:929-933

13. Panza JA, Garcia CE, Kilcoyne CM, Quyyumi AA, Cannon III RO 1995 Impaired endothelium-dependent vasodilation in patients with essential hypertension: evidence that nitric oxide abnormality is not localized to a single signal transduction pathway. Circulation 91:1732-1738

14. Ghiadoni L, Taddei S, Virdis A, Sudano I, Di LV, Meola M, Di Venanzio L, Salvett A 1998 Endothelial function and common carotid artery wall thickening in patients with essential hypertension. Hypertension 32:25-32

15. Luscher TF, Vanhoutte PM 1986 Endothelium-dependent contractions to acetylcholine in the aorta of the spontaneously hypertensive rat. Hypertension 8:344-348

16. Watt PA, Thurston H 1989 Endothelium-dependent relaxation in resistance vessels from the spontaneously hypertensive rats. J Hypertens 7:661-666

17. Martin H, Hu J, Gennser G, Norman M 2000 Impaired endothelial function and increased carotid stiffness in 9-year-old children with low birthweight. Circulation 102:2739-2744

18. Leeson CP, Whincup PH, Cook DG, Donald AE, Papacosta O, Lucas A, Deanfield JE 1997 Flow-mediated dilation in 9- to 11-year-old children: the influence of intrauterine and childhood factors. Circulation 96:2233-2238

19. Leeson CP, Kattenhorn M, Morley R, Lucas A, Deanfield JE 2001 Impact of low birthweight and cardiovascular risk factors on endothelial function in early adult life. Circulation 103:1264-1268

20. Holemans K, Gerber R, Meurrens K, De Clerck F, Poston L, Van Assche FA 1999 Maternal food restriction in the second half of pregnancy affects vascular function but not blood pressure of rat female offspring. Br J Nutr 81:73-79

21. Franco MC, Arruda RM, Dantas AP, Kawamoto EM, Fortes ZB, Scavone C, Carvalho MH, Tostes RC, Nigro D 2002 Intrauterine undernutrition: expression and activity of the endothelial nitric oxide synthase in male and female adult offspring. Cardiovasc Res 56:145-153

22. Ozaki T, Nishina H, Hanson MA, Poston L 2001 Dietary restriction in pregnant rats causes gender-related hypertension and vascular dysfunction in offspring. J Physiol (Lond) 530:141-152

23. Langley-Evans SC, Phillips GJ, Benediktsson R, Gardner DS, Edwards CR, Jackson AA, Seckl JR 1996 Protein intake in pregnancy, placental glucocorticoid metabolism and the programming of hypertension in the rat. Placenta 17:169-172

24. Langley-Evans SC, Gardner DS, Jackson AA 1996 Association of disproportionate growth of fetal rats in late gestation with raised systolic blood pressure in later life. J Reprod Fertil 106:307-312

25. Langley SC, Jackson AA 1994 Increased systolic blood pressure in adult rats induced by fetal exposure to maternal low protein diets. Clin Sci (Lond) 86:217-222

26. Gardner DS, Jackson AA, Langley-Evans SC 1997 Maintenance of maternal dietinduced hypertension in the rat is dependent on glucocorticoids. Hypertension 30:1525-1530

27. Dahri S, Snoeck A, Reusens-Billen B, Remacle C, Hoet JJ 1991 Islet function in offspring of mothers on low-protein diet during gestation. Diabetes 40(suppl 2):115120

28. Langley SC, Browne RF, Jackson AA 1994 Altered glucose tolerance in rats exposed to maternal low protein diets in utero. Comp Biochem Physiol Physiol 109:223-229

28a.Torrens C, Brawley L, Barker AC, Itoh S, Poston L, Hanson MA (2003) Maternal protein restriction in the rat impairs resistance artery but not conduit artery function in pregnant offspring. J Physiol 547:77-84

29. Itoh S, Brawley L, Wheeler T, Anthony FW, Poston L, Hanson MA 2002 Vasodilation to vascular endothelial growth factor in the uterine artery of the pregnant rat is blunted by low dietary protein intake. Pediatr Res 51:485-491

30. Langley-Evans SC, Welham SJ, Sherman RC, Jackson AA 1996 Weanling rat exposed to maternal low-protein diets during discrete periods of gestation exhibit differing severity of hypertension. Clin Sci (Lond) 91:607-615

31. Langley-Evans SC 2000 Critical differences between two low protein diet protocols in the programming of hypertension in the rat. Int J Food Sci Nutr 51:11-17

32. Hoet JJ, Hanson MA 1999 Intrauterine nutrition: its importance during critical periods for cardiovascular and endocrine development. J Physiol (Lond) 514:617-627

33. Kwong WY, Wild AE, Roberts P, Willis AC, Fleming TP 2000 Maternal undernutrition during the preimplantation period of rat development causes blastocyst abnormalities and programming of postnatal hypertension. Development 127:4195-4202

34. Desai M, Crowther NJ, Lucas A, Hales CN 1996 Organ-selective growth in the offspring of protein-restricted mothers. Br J Nutr 76:591-603

35. Desai M, Byrne CD, Zhang J, Petry CJ, Lucas A, Hales CN 1997 Programming of hepatic insulin-sensitive enzymes in offspring of rat dams fed a protein-restricted diet. Am J Physiol 272:G1083-G1090

36. Ozanne SE, Martenz ND, Petry CJ, Loizou CL, Hales CN 1998 Maternal low protein diet in rats programmes fatty acid desaturase activities in the offspring. Diabetologia 41:1337-1342

37. Bertram C, Trowern AR, Copin N, Jackson AA, Whorwood CB 2001 The maternal diet during pregnancy programs altered expression of the glucocorticoid receptor and type $211 \beta$-hydroxysteroid dehydrogenase: potential molecular mechanisms underlying the programming of hypertension in utero. Endocrinology 142:2841-2853

38. Langley-Evans SC, Jackson AA.1995 Captopril normalises systolic blood pressure in rats with hypertension induced by fetal exposure to maternal low protein diets. Comp Biochem Physiol A Physiol 110:223-228

39. Langley-Evans SC, Jackson AA 1996 Rats with hypertension induced by in utero exposure to maternal low-protein diets fail to increase blood pressure in response to a high salt intake. Ann Nutr Metab 40:1-9
40. Woods LL, Ingelfinger JR, Nyengaard JR, Rasch R 2001 Maternal protein restriction suppresses the newborn renin-angiotensin system and programs adult hypertension in rats. Pediatr Res 49:460-467

41. Sherman RC, Langley-Evans SC 2000 Antihypertensive treatment in early postnatal life modulates prenatal dietary influences upon blood pressure in the rat. Clin Sci (Lond) 98:269-275

42. Woodall SM, Johnston BM, Breier BH, Gluckman PD 1996 Chronic maternal undernutrition in the rat leads to delayed postnatal growth and elevated blood pressure of offspring. Pediatr Res 40:438-443

43. Kind KL, Simonetta G, Clifton PM, Robinson JS, Owens JA 2002 Effect of maternal feed restriction on blood pressure in the adult guinea pig. Exp Physiol 87:469-477

44. Langley-Evans SC, Welham SJM, Jackson AA 1999 Fetal exposure to maternal low-protein diets impairs nephrogenesis and promotes hypertension in the rat. Life Sci 64:965-974

45. Langley-Evans SC, Gardner DS, Welham SJM 1998 Intrauterine programming of cardiovascular disease by maternal nutritional status. Nutrition 14:39-47

46. Christensen KL, Mulvany MJ 1993 Mesenteric arcade arteries contribute substantially to vascular resistance in conscious rats. J Vasc Res 30:73-79

47. Koukkou E, Ghosh P, Lowy C, Poston L 1998 Offspring of normal and diabetic rats fed saturated fat in pregnancy demonstrate vascular dysfunction. Circulation 98:2899-2904

48. Huang A, Koller A 1997 Endothelin and prostaglandin $\mathrm{H}_{2}$ enhance arteriolar myogenic tone in hypertension. Hypertension 30:1210-1215

49. Gao YJ, Lee R 2001 Hydrogen peroxide induces a greater contraction in mesenteric arteries of spontaneously hypertensive rats through thromboxane $\mathrm{A}_{2}$ production. $\mathrm{Br} \mathrm{J}$ Pharmacol 134:1639-1646

50. Busse R, Fleming I 1999 Nitric oxide, nitric oxide synthase, and hypertensive vascular disease. Curr Hypertens Rep 1:88-95

51. Taddei S, Virdis A, Ghiadoni L, Sudano I, Salvetti A 2001 Endothelial dysfunction in hypertension. J Cardiovasc Pharmacol 38:S11-S14

52. Taddei S, Virdis A, Mattei P, Ghiadoni L, Sudano I, Salvetti A 1996 Defective L-arginine-nitric oxide pathway in offspring of essential hypertensive patients. Circulation 94:1298-1303

52a. Lamireau D, Nuyt AM, Hou X, Bernier S, Beauchamp M, Gobeil F, Jr., Lahaie I, Varma DR, Chemtob S 2002 Altered vascular function in fetal programming of hypertension. Stroke 33:2992-2998

53. Franco MC, Dantas AP, Akamine EH, Kawamoto EM, Fortes ZB, Scavone C, Tostes RC, Carvalho MH, Nigro D 2002 Enhanced oxidative stress as a potential mechanism underlying the programming of hypertension in utero. J Cardiovasc Pharmacol 40:501-509

54. Brawley L, Torrens C, Itoh S, Barker AC, Poston L, Clough GF, Hanson MA 2002 Dietary protein restriction attenuates acetylcholine-induced nitric oxide levels in small mesenteric arteries from pregnant rat dams. FASEB J 16:A104(abstr)

55. Wirth KJ, Linz W, Wiemer G, Scholkens BA 1996 Differences in acetylcholine- and bradykinin-induced vasorelaxation of the mesenteric vascular bed in spontaneously hypertensive rats of different ages. Naunyn Schmiedebergs Arch Pharmacol $354: 38-43$

56. Berguer R, Hottenstein OD, Palen TE, Stewart JM, Jacobson ED 1993 Bradykinininduced mesenteric vasodilation is mediated by $\mathrm{B} 2$-subtype receptors and nitric oxide. Am J Physiol 264:G492-G496

57. Brawley L, Itoh S, Anthony F, Poston L, Wheeler T, Hanson MA 2001 The effect of protein restriction on acetylcholine-induced vasorelaxation in pregnant rats. J Vasc Res 38:No.94, 38

58. Madeddu P, Emanueli C, Gaspa L, Salis B, Milia AF, Chao L, Chao J 1999 Role of the bradykinin B2 receptor in the maturation of blood pressure phenotype: lesson from transgenic and knockout mice. Immunopharmacology 44:9-13

59. Madeddu P, Milia AF, Salis MB, Gaspa L, Gross W, Lippoldt A, Emanueli C 1998 Renovascular hypertension in bradykinin B2-receptor knockout mice. Hypertension 32:503-509

60. Waldman SA, Murad F 1987 Cyclic GMP synthesis and function. Pharmacol Rev 39:163-196

61. Kagota S, Tamashiro A, Yamaguchi Y, Sugiura R, Kuno T, Nakamura K, Kunitomo M 2001 Downregulation of vascular soluble guanylate cyclase induced by high salt intake in spontaneously hypertensive rats. Br J Pharmacol 134:737-744

62. Kloss S, Bouloumie A, Mulsch A 2000 Aging and chronic hypertension decrease expression of rat aortic soluble guanylyl cyclase. Hypertension 35:43-47

63. Marques M, Millas I, Jimenez A, Garcia-Colis E, Rodriguez-Feo JA, Velasco S, Barrientos A, Casado S, Lopez-Farre A 2001 Alteration of the soluble guanylate cyclase system in the vascular wall of lead-induced hypertension in rats. J Am Soc Nephrol 12:2594-2600

64. Morawietz H, Weber M, Rueckschloss U, Lauer N, Hacker A, Kojda G 2001 Upregulation of vascular NAD(P)H oxidase subunit gp91phox and impairment of the nitric oxide signal transduction pathway in hypertension. Biochem Biophys Res Commun 285:1130-1135

65. Ruetten H, Zabel U, Linz W, Schmidt HH 1999 Downregulation of soluble guanyly cyclase in young and aging spontaneously hypertensive rats. Circ Res 85:534-541

66. Kauffman RF, Schenk KW, Utterback BG, Crowe VG, Cohen ML 1987 In vitro relaxation by new inotropic agents: relationship to phosphodiesterase inhibition and cyclic nucleotides. J Pharmacol Exp Ther 242:864-872

67. Delpy E, Coste H, le Monnier de Gouville AC 1996 Effects of cGMP elevation on isoprenaline-induced increase in cAMP and relaxation in rat aortic smooth muscle: role of phosphodiesterase 3. Br J Pharmacol 119:471-478

68. Komas N, Lugnier C, Stoclet J-C 1991 Endothelium-dependent and independent relaxation of rat aorta by cyclic nucleotide phosphodiesterase inhibitors. Br J Pharmacol 10:495-503 